\title{
Formação e reforma do sistema monetário internacional: aspectos teóricos e o caso dos acordos de Bretton Woods
}

Formation and reform of the international monetary
system: theoretical aspects and the case of the Bretton
Woods Agreement.

Formación y reforma del sistema monetario internacional: aspectos téoricos y el caso de los Acuerdos de Bretton Woods.

\author{
Adriano Vilela Sampaio
}

dade Estadual de Campinas. Professor da Universidade Federal Fluminense: Niterói, RJ, Brasil. ORCID: https://orcid org/0000-0002-1866-4118. Contato: adrianovs@id.uff.br.

DOl: 10.5752/P.2317-773X.2021v9.n2.p114
Recebido em: 12 de dezembro de 2019

Aceito em: 20 de setembro de 2020

\begin{abstract}
RESUMO
O artigo tem como foco a formação e transição do sistema monetário internacional (SMI) e tem como principal objetivo analisar, a partir da perspectiva neogramsciana, os fatores que permitiram a ampla reformulação do SMI nos Acordos de Bretton Woods. Buscou-se na Economia Política Internacional (EPI) um arcabouço teórico que permitisse entender a formação e estabilidade do SMI a partir de uma análise integrada entre economia e política. De acordo com a abordagem neogramsciana, mudanças no equilíbrio de poder não necessariamente implicam mudanças nos regimes internacionais, pois o estabelecimento de uma hegemonia internacional se faz necessário. Argumenta-se que o sucesso dos Acordos de Bretton Woods em promover uma profunda mudança no SMI não se deveu somente à excepcionalidade do momento pós-guerra e à liderança dos Estados Unidos (EUA), mas também ao processo de mudanças sociais, políticas e econômicas que tomou forma nas décadas anteriores e culminou em uma nova hegemonia internacional. É defendido também que embora a crise de 2008 tenha gerado um momento propício a mudanças e que tenha havido reformas em elementos importantes do SMI, mudanças profundas no sistema só
\end{abstract} viriam com uma transição hegemônica, algo ainda fora de perspectiva.

Palavras-chave: Sistema monetário internacional. Hegemonia. Bretton Woods. Países emergentes. Economia Política Internacional.

\section{ABSTRACT}

This paper focus on the formation and transition of the international monetary system (IMS) and its main objective is to analyze, based on the neogramscian 
approach the factors that allowed the broad reformulation of the IMS in the Bretton Woods Accords. The International Political Economy (IPE) provides a theoretical framework that helps to understand the formation and stability of the IMS from an integrated analysis between economics and politics. According to the neogramscian approach, changes in the balance of power do not necessarily imply changes in international regimes, since the establishment of an international hegemony is necessary. It is argued that the success of the Bretton Woods Accords in promoting profound change in the IMS was due not only to the postwar momentum and US leadership, but also to the process of social, political and economic change that took shape in previous decades and culminated in a new international hegemony. It is also argued that although the 2008 crisis generated a momentum to change and that there were reforms in important elements of the IMS, profound changes in the system would only arrive with a hegemonic transition, something still out of sight.

Keywords: International monetary system. Hegemony. Bretton Woods. Emerging countries. International political economy.

\section{RESUMEN}

El artículo se centra en la formación y transición del sistema monetario internacional (SMI) y su objetivo principal es investigar los factores que permitieron la amplia revisión del SMI en los Acuerdos de Bretton Woods. Se buscó en la Economía Política Internacional (EPI) un marco teórico que permitiera comprender la formación y la estabilidad del SMI a partir de un análisis integrado entre economía y política. Según el enfoque neogramsciano, los cambios en el equilibrio de poder no implican necesariamente cambios en los regímenes internacionales, porque es necesario el establecimiento de una hegemonía internacional. Se argumenta que el éxito de los Acuerdos de Bretton Woods en lograr un cambio profundo en el SMI se debió no solo al impulso de la posguerra y al liderazgo de los EE. UU., sino también al proceso de cambio social, político y económico que tomó forma en decenios anteriores y culminó en una nueva hegemonía internacional. También se argumenta que si bien la crisis de 2008 generó un impulso para el cambio y que hubo reformas en elementos clave del SMI, los cambios profundos en el sistema solo vendrían con una transición hegemónica, algo aún fuera de perspectiva.

Palabras clave: Sistema monetario internacional. Hegemonía. Bretton Woods. Países emergentes. Economia politica internacional.

Introdução

Crises econômicas tendem a ser momentos em que se acirram os questionamentos acerca do funcionamento das estruturas vigentes, abrindo espaço para mudanças - radicais ou incrementais. Após a crise financeira global de 2008 , por exemplo, muito foi dito sobre a necessidade de se reformar o sistema monetário internacional (SMI). Outra questão que ganhou força foi o papel que os chamados países emergentes podem ter na economia mundial nas próximas décadas e o maior espaço que deveria ser dado a eles nas decisões relativas às questões econômicas internacionais.

Sobre o primeiro aspecto, os Acordos de Bretton Woods são sempre lembrados como exemplo de cooperação e vontade política para mudanças. O trecho a seguir do discurso do então presidente francês Nicolas Sarkozy no Fórum Econômico Mundial em Davos em janeiro de 2010 ilustra bem esse sentimento: "A prosperidade do pós-guerra se deve 
2. "The prosperity of the post-war era owed a great deal to Bretton Woods, to its rules and its institutions. That is exactly what we need today; we need a new Bretton Woods". Disponível em https://www.europeanbusinessreview. eu/page.asp?pid=702. Acesso em

02/12/2019

3. Se ela é lastreada em outra moeda ou bem, emitida por um país ou uma instituiçã̃o internacional, etc.

4. Não é objetivo deste artigo analisar de que forma tais elementos condicionam o SMI. em grande parte aos acordos de Bretton Woods, suas regras e instituições. É exatamente isso que precisamos hoje; precisamos de um novo Bretton Woods"2. No entanto, o sucesso das reuniões de Bretton Woods foi resultado não somente de um momento oportuno em que mudanças profundas teriam mais aceitação. À época das reuniões que levaram aos Acordos, havia grande aceitação em torno de políticas como taxas fixas de câmbio e o uso de controles de capitais.

Em relação ao papel dos países emergentes é necessária uma análise que vá além de identificar o peso que algumas dessas economias ou o grupo como um todo poderá ter na economia global. É necessário o entendimento de como um maior peso econômico pode se traduzir em poder efetivo nas questões internacionais (via instituições, acordos, fóruns, etc) e, principalmente, de que tipo de sistema internacional eles estão buscando. Buscou-se na Economia Política Internacional (EPI) uma abordagem que permitisse o entendimento de como a emergência de novos atores está relacionada às mudanças nos sistemas econômicos internacionais (SEI).

Mudanças profundas no SMI só ocorrem se houver uma coerência mínima em torno dos elementos que o compõe. Diferentes Estados e grupos de interesse buscarão consensos em torno dos elementos que consideram serem os melhores aos seus interesses e de grupos aliados e subordinados. Como afirma (WARNAAR, 2012), na esfera internacional a mudança pode ser encontrada onde grupos de Estados achem ou criem espaços para desafiar o modo pelo qual as relações internacionais são organizadas, seja pelo enfraquecimento do sistema vigente, seja pela criação de uma alternativa contra hegemônica. O objetivo deste artigo é analisar, a partir da perspectiva neogramsciana, os fatores que permitiram a ampla reformulação do SMI nos Acordos de Bretton Woods. A hipótese aqui adotada é a de que o sucesso dos Acordos de Bretton Woods em promover uma profunda mudança no SMI não se deveu somente à excepcionalidade do momento pós-guerra e à liderança dos EUA, mas também ao processo de mudanças sociais, políticas e econômicas que tomou forma nas décadas anteriores e levou à formação de uma nova hegemonia internacional.

Além desta introdução, o artigo conta com mais duas seções e as considerações finais. Na primeira é feita a apresentação da abordagem neogramsciana, que serve de base à análise do processo histórico de Bretton Woods. A segunda trata do processo ocorrido nas décadas de 1920 e 1930 no qual as políticas liberais foram sendo abandonada em detrimento de políticas intervencionistas e como esse processo influenciou as tentativas de reforma do SMI feita à época.

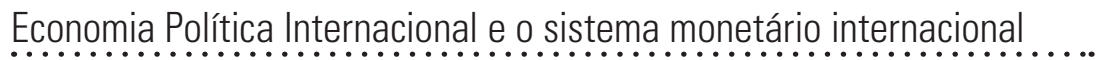

A configuração do SMI pode ser dada a partir de seus componentes, quais sejam, o regime cambial prevalecente nos países centrais, o grau de mobilidade de capitais, a natureza da divisa-chave ${ }^{3}$ e as instituições econômicas internacionais. Diferentes combinações desses elementos condicionarão a dinâmica do sistema, dando-lhe um caráter mais ou menos expansivo ou recessivo, simétrico ou assimétrico, estável ou instável, etc ${ }^{4}$. 
Em suma, o SMI não deve ser tomado como uma estrutura neutra, pois diferentes configurações podem proporcionar benefícios assimétricos aos diferentes agentes participantes (Estados, investidores, empresas, etc.).

Dada essa não neutralidade, para o estudo do SMI a partir da EPI é necessário entender como diferentes autores(as) tratam a formação, estabilidade e mudanças de sistemas econômicos internacionais (SEI) e suas relações com a estrutura política internacional, ou seja, como promovem a integração de elementos políticos e econômicos. Nesta seção, busca-se mostrar como a questão da formação e transação de sistemas internacionais é tratada nessa perspectiva, contemplando também uma análise crítica de algumas das principais correntes da EPI sobre o tema ${ }^{5}$.

Uma importante referência no campo da EPI, que ocupou espaço importante no debate em décadas anteriores, é Kindleberger (1987). Em sua análise acerca das causas da crise de 1929, o autor atribui a instabilidade do período entreguerras à falta de um país hegemônico que pudesse prover estabilidade ao sistema. Enquanto o Reino Unido tinha a disposição para exercer tal liderança, faltava-lhe capacidade efetiva para a tarefa. Já os EUA, por seu poderio econômico e militar, tinham a capacidade, mas não a disposição ${ }^{6}$. Na abordagem do autor, em momentos de divergências de interesses, a economia internacional precisaria de um líder, um país que pudesse definir padrões de conduta e que aceitasse os "fardos" do sistema. Antes mesmo de Kindleberger, Gilpin (1971) afirmou que a instabilidade econômica do período entreguerras estava relacionada à transição de lideranças: "Londres não tinha capacidade e Nova York não tinha a disposição para reestruturar a economia internacional após seu desmonte na Primeira Guerra Mundial"' (GILPIN, 1971, p. 407). A ideia da necessidade de um hegemon para dar estabilidade ao sistema foi aprofundada por diversos outros autores, no que ficou conhecido como a teoria da estabilidade hegemônica (TEH). A TEH, no entanto, não é um corpo de ideias homogêneas, mas um conjunto de conceitos em torno da preocupação com o fornecimento de bens públicos que permitissem um melhor funcionamento da economia internacional. De acordo com Cohen (2008), a THE poderia ser dividida em duas versões, a neorrealista e a neoliberal (ou institucionalista).

$\mathrm{Na}$ versão neorrealista da $\mathrm{TEH}$, o fornecimento de bens públicos seria feito pelo país mais poderoso ${ }^{8}$, que moldaria o regime econômico internacional de acordo com seus interesses (sendo que os interesses militares sempre estariam acima dos econômicos). Regimes internacionais podem ser entendidos como princípios, normas, regras e processos de tomada de decisão em torno dos quais as expectativas dos agentes convergem em uma dada área de interesse (KRASNER, 1982). Para Gilpin (2001), a economia neoclássica forneceria um instrumental adequado para o entendimento do funcionamento dos mercados e de como as forças de mercado afetam a economia, no entanto, tal abordagem seria insuficiente ao considerar que os mercados funcionam em um vácuo político. Haveria, portanto, a necessidade de se acrescentar ao estudo dos mercados uma análise política, de forma a entender como os diferentes atores (sendo o Estado-nação o mais importante) agiriam para manipular as forças de mercado de acordo com seus interesses. Neste caso, a conexão entre eco-
5. Sem a pretensão de uma análise exaustiva de como essas diferentes correntes tratam a questão.

6. 0 congresso estadunidense foi contrário até mesmo à participação do país na Liga das Nações.

7. London was unable and New York was unwilling to restructure the international economy disrupted by the First World War.

8. Embora haja variações nos conceitos de poder utilizados pelos autores dessa corrente e da versão neoliberal, para ambos, poder é entendido como recursos materiais (militares, econômicos, população, etc.) detidos por um país. 
9. Uma premissa central das correntes realista e neorrealista, assim como a ideia de que os Estados são os atores centrais na formação de sistemas internacionais.

10. Como na microeconomia neoclássica, em que o funcionamento de um mercado e o comportamento das firmas é deduzido de sua estrutura (concorrência perfeita, oligopólio ou monopólio) não sendo necessário conhecer as especificidades de cada firma.

11. Pelo excessivo peso dado à estrutura, em detrimento das unidades, essa análise ficou conhecida como realismo estrutural

12. Como pode ser visto em Waltz (1979) e Krasner (1976). nomia e política se daria com a primeira sendo subordinada à segunda ${ }^{9}$. Tal subordinação é ainda mais radical na abordagem de Waltz (1979), para quem a dinâmica do sistema (o comportamento das unidades e os resultados de suas interações) poderia ser deduzida a partir de sua estrutura ${ }^{10}$, negligenciando-se os atributos das unidades (países). Nesse sentido, uma mudança do sistema só poderia vir de uma mudança na sua estrutura, ou seja, do equilíbrio de poder" ${ }^{11}$ Portanto, na versão neorrealista da TEH, a construção e a estabilidade dos regimes estariam diretamente ligadas à existência de um país hegemônico e um reequilíbrio de poder levaria necessariamente à necessidade de se reconstruir o regime de forma a acomodar novos interesses.

Na versão neoliberal da THE, o argumento de Keohane (1984) e Keohane e Nye (1989) é que a interdependência entre os países levaria à criação de regimes internacionais e os benefícios proporcionados por eles (como a redução da incerteza e de falhas de mercado) e os altos custos de se construir outros, fariam com que estes sobrevivessem mesmo quando houvesse mudanças no equilíbrio de poder. Nessa perspectiva, o poder militar dos Estados daria lugar a uma ordem política e econômica mundial em que os bens públicos seriam fornecidos por regimes supranacionais que prescindiriam de um hegemon (FIORI, 2005). Por isso também pode ser chamada de versão institucionalista ou teoria dos regimes internacionais. A preocupação da abordagem neoliberal da TEH sobre a importância (ou não) de uma liderança para a estabilidade dos SEI, refletia o contexto do fim da década de 1970 e início da década de 1980, quando havia um aparente declínio da hegemonia dos EUA no bloco capitalista e um acirramento da instabilidade do SMI com o abandono do regime de Bretton Woods pelos países centrais.

Apesar das diferenças apontadas entre as duas versões, em ambas o funcionamento dos regimes é investigado a partir da interação entre unidades em uma dada estrutura. Tais unidades seriam movidas por preferências dadas, sempre avaliando os custos e benefícios de cada ação, o que Ruggie (1998) chamou de abordagem neoutilitarista. Não haveria um questionamento das preferências dos atores, elas seriam dadas e a-históricas (COX, 1981). Para Cohen (2008), tais abordagens estariam seguindo o mesmo caminho da economia neoclássica, buscando formalizar a teoria e reduzi-la a modelos passíveis de serem testados empiricamente. O referencial é a microeconomia neoclássica e seus agentes representativos ${ }^{12}$. A partir da premissa de que os Estados são unidades unitárias (homogêneas) e racionais (como o agente representativo da economia neoclássica), as interações entre eles poderiam ser analisadas pela lógica da escolha racional e com o auxílio da teoria dos jogos (STRANGE, 1996, p. 22).

A consequência de uma análise a partir de agentes racionais, com preferências dadas é que ela não é capaz de explicar a mudança a partir de seus próprios elementos, ou seja, endogenamente. Como diz Ruggie (1998, p. 874), tais abordagens têm somente uma lógica reprodutiva e não transformativa. Portanto, se o objetivo é analisar mudanças ou perspectivas de mudança, tal abordagem se mostraria insuficiente. Para Rupert (2010), tais abordagens trabalham com atores sociais pré-concebidos e por isso não seriam capazes de entender o processo histórico pelo qual tais 
atores foram concebidos e, dessa forma, não abriria espaço para o surgimento de estruturas alternativas. É necessária, portanto, uma abordagem que não só explique a participação de diferentes atores na formação dos SEI, mas também que coloque as preferências dos atores como objeto de análise e as explique dentro de um contexto histórico. Também é fundamental que a integração entre economia e política não seja apenas a adição de elementos políticos à teoria neoclássica.

Para Scandiucci Filho (2000), a abordagem neogramsciana forneceria uma estrutura teórica em que a economia e a política não são autônomas, mas se movem conjuntamente. Nela são analisados os conflitos internos dos Estados e a forma pela qual os interesses econômicos domésticos são articulados politicamente, refletindo-se em suas políticas. Se as relações econômicas não ocorrem em um vácuo político, o mesmo valeria para as ações do Estado. O Estado teria que ser visto em sua relação com a sociedade civil, como um complexo estado/sociedade (GILL, 1990) e não como uma unidade homogênea.

O conceito de hegemonia é central para a abordagem neogramsciana. Segundo Arrighi (2004; 2008), a definição gramsciana de hegemonia vai além da pura dominação. Enquanto a última se refere a uma situação em que o poder é exercido pela coerção, na primeira ele é sustentado por uma liderança intelectual e moral, com a coerção funcionando como último recurso. Nessa visão, uma ordem hegemônica seria uma combinação entre coerção e consentimento, mas que o consenso, e não a coerção, é a característica fundamental que explica a relação entre classes e entre o Estado e a sociedade civil. Além disso, em uma situação de hegemonia gramsciana, os grupos dominantes articulam uma visão que é vista como servindo ao interesse de todos, inclusive de grupos subordinados (RUPERT, 2010).

Para Cox (1983, p. 172), a hegemonia internacional poderia ser expressa como normas universais, instituições e mecanismos que estabelecem regras gerais de comportamento para Estados e para as forças da sociedade civil que atuam além das fronteiras nacionais. Seria, portanto, mais que uma ordem entre Estados, mas uma situação em que os interesses do Estado mais poderoso ${ }^{13}$ teriam de ser compatíveis não só com os interesses de outros Estados, mas também com forças da sociedade civil que operam globalmente. Segundo o autor, o estabelecimento de uma hegemonia internacional viria da internacionalização da hegemonia doméstica estabelecida pela classe dominante no Estado hegemônico, em que suas instituições econômicas e sociais, cultura e tecnologia se tornam padrões a serem reproduzidos no plano internacional.

A abordagem neogramsciana permitiria, portanto, um melhor entendimento do processo pelo qual o ganho de poder econômico por parte de um ou mais países se traduz em mudanças no sistema. Nessa visão, mudanças nos regimes dependem não só do poder material, mas também de uma ideologia aceita por outros países e instituições que preservem e reforcem os dois elementos anteriores. É importante destacar que a diferença dessa abordagem para as de caráter neoutilitaristas não é apenas a adição da ideologia e instituições ao poder material para a definição de hegemonia. Nessa abordagem se trabalha com outro conceito de Estado (comple-
13. Para 0 autor, a superioridade de um Estado não se resume ao poder material, outro requisito fundamental seria a existência de uma hegemonia doméstica plenamente estabelecida. 
14. Por ordem entende-se a dinâmica do sistema, o modo pelo qual as coisas funcionam uma estrutura em que não necessariamente prevalece a ordem. E mundial não se refere à totalidade dos países, sendo ela limitada pelo alcance das prováveis interações (COX, 1981). xo Estado/sociedade civil), a hegemonia está fundada em relações sociais e as relações internacionais não se limitam aos Estados (SCANDIUCCI FILHO, 2000). Outra diferença fundamental é que nessa abordagem a análise é sempre histórica, ou seja, não se pode tomar como dado uma suposta natureza dos agentes, ou mesmo definir a priori uma hierarquia entre uma estrutura política e econômica, como no neorrealismo, por exemplo. Ou seja, seria necessário que a configuração do sistema fosse vista como uma combinação histórica e não como uma estrutura dada. Outro ponto a ser destacado é que a hegemonia internacional não poderia ser vista como uma estrutura que determina as ações, mas que as constrange, deixando também espaço para hegemonias rivais emergirem (COX, 1983).

Se, por um lado, deixa-se de lado a existência de um país dominante como condição necessária para a estabilidade dos SEI, por outro coloca-se a hegemonia internacional como um fator essencial explicando a formação e o declínio dos diferentes sistemas. Assim, a análise não só deve explicitar a orientação do sistema a partir de seus componenentes e propriedades, mas seus componenes e propriedades também devem ser vistos como resultado de uma orientação mais geral, uma hegemonia.

Segundo Scandiucci Filho (2000), a superação do debate entre realistas e liberais requer uma abordagem em que economia e política sejam indissociáveis. Trazendo essa perspectiva para a formação e mudanças do SMI, seria preciso analisar a hegemonia que o condiciona e sua orientação não pode ser vista somente como uma consequência "mecânica" de seus componentes. Essa orientação seria fruto da hegemonia vigente (se houver), mas, diferentemente de abordagens neoutilitaristas, essa relação não pode ser colocada como uma causalidade com sentido pré-definido. Dessa forma, propõe-se tratar os componentes não apenas como consequência, mas também como instrumentos necessários à orientação do SMI e à constituição da hegemonia.

O SMI não seria somente construído a partir da hegemonia, mas ela própria seria construída a partir de um SMI que reproduzisse sua orientação. Ou seja, o SMI, seus componentes e sua orientação, têm de ser colocados como partes integrantes da hegemonia. Os componentes do sistema podem ser explicados a partir da hegemonia, mas ao mesmo tempo se tornam condições necessárias a reprodução e manutenção desta. Com isso em vista, a seção seguinte busca mostrar como os acordos de Bretton Woods levaram a um SMI em seus elementos componentes davam uma orientação consonante com a hegemonia vigente que vinha se consolidando.

Bretton Woods: o processo e o momento

Nesta seção, é discutido como se formou uma nova hegemonia internacional que deu origem a ordem mundial ${ }^{14}$ de Bretton Woods. Foi um processo que levou tempo e que não ocorreu sem resistências. As dificuldades para se consolidar essa nova hegemonia podem ser vistas nas tentativas de se reorganizar o SMI durante o entreguerras. As propostas discutidas e aprovadas nos Acordos de Bretton Woods e que moldaram o SMI nas duas décadas posteriores não surgiram de um vácuo, nem são 
frutos simplesmente do momento extraordinário de esforço para moldar um novo sistema para o pós-guerra. Elas podem ser explicadas também a partir de um processo que envolveu a consolidação dos EUA como o poder militar e econômico dominante (ao menos do bloco capitalista), e mudanças políticas em diversos países, onde a correlação de forças internas foi alterada. Como destaca Helleiner (2010), Bretton Woods foi resultado de um momento e de um processo, que são analisados nas seções seguintes.

\section{O processo: os conservadores anos 1920}

Após a Primeira Guerra Mundial, não se buscava um novo SMI, mas o restabelecimento do padrão-ouro.

\section{O propósito daquela década era profundamente conservador e expres- sava a convicção praticamente universal de que somente pelo restabe- lecimento do sistema pré-1914, 'desta vez em fundações sólidas', seria possível restaurar a paz e a prosperidade. (...) foi só nos anos 1930s que elementos inteiramente novos se integraram ao modelo da história oci- dental. (POLANYI, 2001, p. 23-24) ${ }^{15}$}

As "sólidas fundações" as quais o autor se refere eram as mesmas que teoricamente sustentaram o sistema nas décadas anteriores, como prioridade ao equilíbrio orçamentário e à baixa inflação.

Apesar desse caráter conservador, Eichengreen (1985) afirma que na década de 1920 os governos tinham ciência de que não poderiam ignorar a interdependência entre as economias nacionais e que havia a necessidade de maior cooperação entre eles. Segundo o autor, a restauração do padrão-ouro foi alcançada com a ajuda de empréstimos da Liga das Nações, dos EUA e do Reino Unido a países em situação de hiperinflação e as bases de tais empréstimos foram acordadas nas conferências internacionais de Bruxelas em 1920 e Gênova em 1922.

Havia, portanto, esforços concentrados e cooperação para a reconstrução do SMI em suas antigas bases. Isso pode ser visto nas resoluções da Conferência Econômica e Financeira de Gênova, ocorrida em 1922. Os britânicos propuseram o retorno ao padrão-ouro e um sistema institucionalizado, com regras formais para autoridades monetárias nacionais (STRANGE, 1976). As fundações do sistema seriam (como antes) o compromisso com orçamentos equilibrados, montantes adequados de reservas internacionais, bancos centrais independentes, baixa inflação e a remoção de controles de capitais (FINK, 1984). Para evitar a concorrência por reservas metálicas, a demanda por ouro pelos bancos centrais seria coordenada por uma comissão internacional. Além disso, para se reduzir o uso do ouro, moedas domésticas "fortes" poderiam complementar as reservas internacionais ou um sistema de compensações internacionais poderia ser usado (FEDERAL RESERVE BOARD, 1922, p. 678). No entanto, embora sendo claramente uma tentativa de se restaurar o antigo sistema em suas bases "sólidas e saudáveis", havia questionamentos acerca de alguns de seus aspectos. As recomendações para a coordenação da demanda e a redução do uso do ouro ${ }^{16}$, por exemplo, visavam reduzir o viés deflacionário do padrão ouro.
15. The intent of that decade was deeply conservative and expressed the almost universal conviction that only the reestablishment of the pre-1914 system, 'this time on solid foundations', could restore peace and prosperity. (...) it was only in the thirties that entirely new elements entered the pattern of Western history.

16. Embora este ainda fosse considerado o regulador financeiro mais seguro (FINK, 1984) 
17. A recusa de França e Reino Unido em incluir esses tópicos na conferência foram, junto com a recusa em negociar com os bolcheviques, determinantes para que os EUA não participassem (FINK, 1984).
O fracasso da Conferência de Gênova em prover um SMI estável pode ser atribuído a dois importantes fatores. Primeiro, à ausência dos EUA, país cuja importância para o sistema tornava qualquer medida inócua caso não fosse adotada por ele. Segundo, às condições política prevalecentes, que não comportariam uma volta ao padrão-ouro, pois esta representava uma tentativa de se (r)estabelecer um velho sistema em um novo mundo. Quando da eclosão da Primeira Guerra Mundial, o processo iniciado em meados do século XIX de criação e fortalecimento de partidos trabalhistas, extensão dos direitos de votos e maior responsabilidade do Estado nas questões sociais (como condições de trabalho e flutuações de renda) estava consolidado nos países centrais (WALLERSTEIN, 2004). Em relação às políticas econômicas, essas mudanças levaram ao abandono do liberalismo em favor de um papel mais intervencionista do Estado. As consequências do baixo crescimento e desemprego não poderiam mais ser ignoradas pelos governos, sob o risco não só de estes perderem o poder, como da própria hegemonia doméstica ser ameaçada por instabilidades políticas e até mesmo uma revolução socialista. Eichengreen (2008) coloca tais mudanças como centrais para determinante para o fracasso da restauração do padrão-ouro nos moldes vigente antes da Primeira Guerra Mundial. Em geral, os países queriam o retorno ao padrão-ouro, mas as diferentes conjunturas econômicas domésticas estabeleceriam as condições e o timing aceito por cada um deles.

Isso ajuda a explicar a impossibilidade de definir mecanismos formais de cooperação e a motivação dos países em adotar comportamentos não cooperativos nos anos seguintes. Nem mesmo os bancos centrais estavam em harmonia. Apesar de haver um documento final destacando a importância da cooperação entre bancos centrais em temas como estabilização de taxa de câmbio, política de crédito e de sonegação de impostos, divergências entre o Federal Reserve (Fed) e o Banco da Inglaterra inviabilizaram a iniciativa. O último queria que os EUA aceitassem mais inflação para ajudar na restauração da conversibilidade da libra. Os EUA, por usa vez, queriam que os britânicos deflacionassem sua economia, o que só pioraria suas já precárias condições econômicas (FINK, 1984).

Em resumo, sabia-se da importância da cooperação e não se deixou de buscar soluções conjuntas e harmonização de políticas. A cooperação era vista como algo desejável e necessário para o sistema. No entanto, esse esforço esbarrava na inconsistência das políticas deflacionárias em relação ao contexto político doméstico dos países centrais, o que impedia que os países assumissem compromissos com as mesmas políticas que vigoravam no regime do padrão-ouro.

Outros fatores que explicam esse fracasso eram questões não resolvidas da Primeira Guerra, principalmente as dívidas e reparações de guerra ${ }^{17}$. Os países derrotados argumentavam que o pagamento das reparações poderia levá-los a situações de instabilidade social e política e os países Aliados estavam pedindo o perdão de seus débitos com os EUA. Naquele momento, os dois lados se mostravam irredutíveis e uma consequência desses obstáculos foi que a colaboração financeira nos anos seguintes se deu majoritariamente em bases bilaterais (EICHENGREEN, 1985, p. 52). 


\section{O processo: os revolucionários anos 1930}

Diferentemente do que ocorreu na década anterior, na década de 1930, a intenção dos formuladores de política no período era buscar novas formas de se gerenciar a economia doméstica e as questões internacionais. O retorno ao padrão-ouro não era mais o objetivo.

Enquanto no fim da Grande Guerra os ideais do século XIX prevaleciam, tendo a sua influência preponderado ao longo da década seguinte, já por volta de 1940 não restavam quaisquer vestígios do sistema internacional e, excetuados alguns enclaves, as nações viviam em um quadro internacional inteiramente novo. (POLANYI, 2001, p. 24) ${ }^{18}$

A grande depressão representou um impulso decisivo para a implementação de políticas intervencionistas que promovessem o crescimento e tirassem os países da recessão. Planejamento central, controles de capitais, protecionismo, políticas fiscais anticíclicas, entre outros instrumentos, passaram a fazer parte da realidade das economias industrializadas. Segundo Helleiner (1994), desde o princípio da década os governos buscaram exercer maior controle sobre questões monetárias restringindo a independência dos bancos centrais e reduzindo a influência do setor financeiro na formulação de políticas. Nos países industrializados, coalizões que incluíam industriais, oficiais de orientação keynesiana e líderes trabalhistas que eram a favor de políticas mais intervencionistas estavam no poder, colocando em prática políticas orientadas ao pleno emprego. Pela primeira vez, as políticas e as crenças do setor financeiro privado e dos bancos centrais estavam sendo questionados e os governos estavam contando com "outsiders" para as questões monetárias internacionais (HELLEINER, 1994). Essas mudanças nas políticas domésticas afetariam o SMI de duas maneiras distintas.

Primeiramente, houve um acirramento de sentimentos nacionalistas. Em um momento em que os países passavam por recessões, questões domésticas, como o desemprego, teriam prioridade sobre o equilíbrio do setor externo ou a estabilidade da taxa de câmbio, ainda que às custas de menor cooperação internacional e do abandono de regras consideradas "sagradas" durante o padrão ouro, como a mobilidade de capitais. A prioridade dada pelos países à manutenção da autonomia de política econômica pode ser vista em três diferentes episódios da década. O fracasso da tentativa de se estabilizar o SMI na Conferência Econômica Mundial em Londres em 1933 seria o primeiro. Havia uma proposta britânica para a criação de um fundo do qual os países poderiam tomar recursos condicionados à estabilização das taxas de câmbio e à remoção de controles de capitais, no entanto, outros países e principalmente os EUA não estavam dispostos a colocar o multilateralismo acima de seus interesses domésticos (STRANGE, 1976). A recuperação da depressão era o objetivo mais imediato. Além disso, soluções cooperativas demandariam tempo e apresentavam riscos, sendo que a situação pedia soluções urgentes. O segundo era a diversidade de regimes cambiais adotados por diferentes países no período. De acordo com Eichengreen (1985), na metade da década de 1930 o Reino Unido praticava uma flutuação administrada, os EUA haviam desvalorizado o dólar e adotado câmbio fixo sem conversibilidade
18. While at the end of the Great War nineteenth century ideals were paramount, and their influence dominated the following decade, by 1940 every vestige of the international system had disappeared and, apart from a few enclaves, the nations were living in an entirely new international setting. 
(exceto para países que ainda seguiam o padrão-ouro), a Alemanha havia adotada uma série de controles de capitais e os países do Bloco do Ouro (França, Bélgica, Holanda, Itália, Polônia e Suíça) mantiveram a livre conversibilidade em ouro. Para o autor, um contexto em que cada país adota o regime cambial de sua conveniência pode ser classificado propriamente como uma "desordem" monetária internacional. E o terceiro foi em relação às funções do Banco de Compensações Internacionais (BIS), criado em 1930. Embora tendo o objetivo de administrar o pagamento das reparações e promover a cooperação entre bancos centrais, a proposta britânica de que o BIS desenvolvesse mecanismos de auxílio à estabilização das taxas de câmbio e aos países enfrentando recessões, não prosperou, principalmente por conta da oposição da França (JAMES, 1996)

A outra maneira pela qual o SMI foi influenciado pelas mudanças nas políticas domésticas foi pelo caráter mais intervencionista das propostas de cooperação. O Acordo Monetário Tripartite de 1936 entre EUA, França e Reino Unido para administrar a desvalorização do franco é um exemplo. Para Eichengreen (1985), o sucesso do Acordo está relacionado ao fato de que, ao contrário do que havia sido proposto em conferências anteriores, os países não teriam de estabelecer taxas fixas de câmbio nem restaurar o padrão-ouro e o alcance das questões sujeitas ao acordo era reduzido. Finalmente, não havia obstáculos políticos intransponíveis, como dívidas e reparações de guerra. Em outubro de 1936 foi assinado o Gold Agreement Act, em que os países se comprometeram a realizar consultas diárias sobre a taxa desejada e sustentá-las por meio da compra e venda de divisas no mercado. A intenção existente em Gênova de centralização e coordenação da demanda de ouro pelos bancos centrais tornou-se realidade, com as transações internacionais sendo limitadas aos bancos centrais e a fundos de estabilização e com restrições ao uso doméstico do ouro. Portanto, mesmo antes da guerra, já estava configurado o caráter que as relações monetárias internacionais assumiriam, qual seja, de um equilíbrio entre cooperação e autonomia de política econômica, que preservasse a liberdade dos países de adotar políticas expansionistas, o que seria a base do embedded liberalism que vigorou nas décadas seguintes. Como observa James (1996), o acordo foi motivado não só pela preocupação com o a estabilidade do SMI, mas também por razões políticas, qual seja a preocupação dos EUA e do Reino Unido de não enfraquecer a França economicamente, o que poderia levar a uma ditadura e facilitar a expansão alemã.

Essas tentativas mostram que havia menos obstáculos políticos para a cooperação que na década anterior, especialmente no que se refere às questões da Primeira Guerra Mundial. Além disso, após a crise de 1929, a precárias condições econômicas levaram à ascensão de regimes autoritário em diversos países e a partir da metade da década de 1930 as hostilidades que desembocariam na Segunda Guerra Mundial já estavam mais claras (HOBSBAWM, 1995), o que aumentou a disposição dos países - especialmente o mais importante deles, os EUA - para a cooperação e para propor soluções adequadas ao novo contexto. Helleiner (2010) chama a atenção para a cooperação entre EUA e América Latina após 1938, em que os EUA financiaram políticas de desenvolvimento 
nos países da região, além de ajudar na estabilização das taxas de câmbio, o que já mostraria a maior disposição do país a assumir um papel de estabilizador para o sistema internacional, por razões tanto econômicas como geopolíticas. Além disso, pode-se destacar o papel desempenhado pela Liga das Nações na organização e administração de resgates a países enfrentando crises no balanço de pagamentos conforme apontado por Strange (1976). Sobre a atuação da Liga das Nações, a autora diz que foi um ponto de partida importante para a cooperação monetária internacional e que a novidade não estava nas operações em si, mas no fato delas serem feitas por uma organização internacional e não por meio de um acordo temporário. Isso, segundo ela, mostrava um crescente sentimento de responsabilidade coletiva, ainda que no começo os alvos fossem países potencialmente ameaçados por revoluções comunistas, o que poderia indicar acima de tudo uma preocupação geopolítica. A provisão de um SMI estável e melhores relações comerciais entre os países eram vistos como medidas que poderiam evitar a eclosão da guerra (EICHENGREEN, 2008).

Portanto, apesar de ser correto apontar o período entreguerras como um período de instabilidade, desordem monetária, falta de coordenação e acirramento de rivalidades, a busca pela cooperação foi uma constante. O problema residia nos termos em que a cooperação se daria, ou seja, que compromissos seriam viáveis dadas as condições políticas domésticas (o complexo estado-sociedade) de cada país. Em um contexto de nacionalismo exacerbado, acordos de cooperação que não levassem em conta os efeitos recessivos sobre a economia doméstica não seriam compatíveis com a relação vigente entre estado e sociedade. Tinha-se, então, a consolidação de um processo, que permitiria que alguns anos depois o momento propício fosse aproveitado para o estabelecimento de um ambicioso plano de cooperação internacional.

\section{O momento: os acordos de Bretton Woods}

O sucesso das reuniões de Bretton Woods não pode ser dissociado do momento de urgência de construção de um novo SMI vigente antes mesmo do fim da guerra. A instabilidade do SMI e as crises econômicas do começo dos anos 1930 que contribuíram para o a eclosão da Segunda Guerra foram valiosas lições aos formuladores de políticas, mostrando a importância de se construir um sistema que provesse estabilidade e permitisse a conciliação entre a necessidade de cooperação internacional com autonomia de política econômica. Os erros do período anterior não poderiam ser repetidos e isso criou um sentimento internacionalista entre os países e um desejo genuíno por um novo começo (JAMES, 1996). Esse sentimento fica bem ilustrado pela passagem abaixo:

Passamos tão mal durante os anos entre as duas Guerras, por falta de um instrumento de controle internacional como este, que o desperdício resultante e a dissipação da riqueza chegaram a ser pouco menores que o custo econômico das próprias guerras; enquanto que a frustração dos esforços dos homens e a deformação de seu padrão de vida não desempenharam papel menos importante no preparo da atmosfera poluída em que os nazistas puderam florescer. (KEYNES, 1984, p. 206) 
19. a novel 'embedded liberal' vision which sought to reconcile the rebuilding of an open multilateral financial system with the new, more interventionist economic practices that had emerged from the Depression experience.

20. 0 comprometimento com 0 embeddedl iberalism não estava restrito às economias avançadas. Na América Latina, por exemplo, os países também buscavam sistemas que permitissem a eles adotarem políticas intervencionistas (HELLEINER, 2010, p. 621)

21. intergovernmental collaboration to facilitate balance-of-payments equilibrium, in an international environment of multilateralism and a domestic context of full employment.
Além disso, quando as propostas começaram a ser desenvolvidas, no início dos anos 1940, elas serviam também como propagada de guerra, visando angariar o apoio de governos aliados e de seus próprios cidadãos para o esforço de guerra, o que fez com que os formuladores de política econômica estivessem dispostos a adotar propostas mais inovadoras do que seria o caso em tempos de paz (HELLEINER, 2010, p. 621). Outro importante fator foi a existência de um país hegemônico. Os países envolvidos na guerra sabiam que a reconstrução da economia mundial dependeria dos EUA e da superioridade incontestável de seu poderio econômico e militar. Os estadunidenses, por sua vez, não apenas estavam cientes do papel crucial que teriam, mas também viram a oportunidade de reproduzir sua hegemonia doméstica no plano internacional. Segundo (BLOCK, 1977), apesar de o New Deal sofrer oposição de setores poderosos (como a comunidade financeira de Nova York), o Departamento do Tesouro, dominado por defensores de políticas intervencionistas (new dealers), ficou responsável pela elaboração das propostas para a Conferência de Bretton Woods.

Portanto, havia uma hegemonia doméstica no país mais poderoso e ela era compatível com o equilíbrio de forças sociais vigentes em outros países, uma das condições necessárias para o estabelecimento da hegemonia internacional, como definida anteriormente. O objetivo comum era desenvolver um sistema capaz de prover autonomia de política econômica aos países e promover a cooperação de forma que os países não tivessem que apelar a políticas competitivas que poderiam levar a novos conflitos. Como afirma Helleiner (2010, p. 620), foi configurado "um novo 'liberalismo enraizado' que buscava reconciliar a reconstrução de um sistema financeiro multilateral liberal com novas práticas econômicas, mais intervencionistas, que emergiram da experiência da Depressão ${ }^{19}$ ". Para Ruggie (1982, p. 393) o objetivo do embedded liberalism era substituir o nacionalismo dos anos 1930 pelo multilateralismo do padrão-ouro e o liberalismo econômico do padrão-ouro pelas políticas intervencionistas vigentes nos anos $1930^{20}$. Os EUA estavam em condições de impor propostas e as discussões foram de fato polarizadas pelas delegações estadunidense e britânica. Ainda assim, as visões eram percebidas como legítimas e compatíveis com os interesses de outros países, de forma que a coerção não explica totalmente o poder dos EUA em moldar o sistema. Embora diferentes, ambas propostas tinham um propósito comum: "cooperação intergovernamental para facilitar o equilíbrio do balanço de pagamentos em um ambiente internacional multilateral e um contexto doméstico de pleno emprego. ${ }^{21 "}$ (RUGGIE, 1982, p. 394-95). Essa visão pode facilmente ser identificada nos elementos fundamentais do SMI sob a ordem de Bretton Woods. O sistema de taxas de câmbio fixas, mas ajustáveis, impediria a prática de desvalorizações competitivas, que não só afetou o comércio internacional como aumentou a rivalidade entre as nações no entreguerras. Mudanças na paridade teriam de ser aprovadas pelo FMI, não seria mais uma opção individual de cada país e sim algo coordenado. Além disso, criava uma possibilidade adicional e não deflacionária para o ajuste da balança comercial.

A aprovação do uso de controles de capitais tinha como objetivo principal manter a autonomia de política econômica dos países. Com 
um menor risco de fugas de capitais, seria mais fácil para os governos sustentarem suas taxas de câmbio e eles ganhariam maior espaço para de política monetária e fiscal (na forma de menores taxas de juros e políticas fiscais anticíclicas) para buscar o pleno emprego. Mesmo antes dos anos 1930 havia suporte para o uso destes, mas em caráter temporário para o caso de oscilações indesejadas dos fluxos. De acordo com James (1996), os então "vilões" da literatura da época - distribuição desigual de ouro, políticas esterilizadoras do Banco da França e do Fed e excessiva inflação da década de 1920 - foram "substituídos" pelos fluxos de capitais e seus efeitos desestabilizadores sobre as economias domésticas. "A restauração de um sistema financeiro multilateral dependia, na visão de quase todo analista, de controles de movimentos de capitais por tempo indeterminado"22. (JAMES, 1996, p. 38). Embora o chefe da delegação estadunidense Harry Dexter White fosse a favor dos controles de capitais, ele teve de superar forte oposição doméstica daqueles que queriam uma ordem financeira internacional liberal ${ }^{23}$ e adaptou suas propostas a tais pressões (BLOCK, 1977).

Em relação às instituições internacionais, o FMI foi criado para propiciar aos países uma fonte de crédito adicional aos mercados privados de capitais. Em combinação com os controles de capitais, o FMI poderia reduzir o poder de investidores privados de "disciplinar" os países, ou seja, poderia reforçar a autonomia de política econômica. $\mathrm{O}$ FMI também seria importante para gerenciar a liquidez internacional. Eichengreen e Flandreau (2009) argumentam que após a restauração do padrão-ouro na década de 1920 não teria havido escassez internacional de ouro, mas uma má distribuição de reservas. Como aponta James (1996), de um lado você tinha países deficitários cuja única opção de ajuste eram as políticas deflacionárias e, de outro, países superavitários que não deixavam a liquidez de suas economias se expandirem. Com um fundo capaz de fornecer recursos aos países enfrentando problemas no balanço de pagamentos os países superavitários não teriam que necessariamente adotar políticas deflacionárias, o que poderia reduzir o viés deflacionário do padrão ouro.

Segundo James (1996), os banqueiros estadunidenses e o Fed de Nova York acusaram os Acordos de Bretton Woods de serem excessivamente inflacionários e que com o FMI países deficitários teriam muito poder e os EUA não teriam outra opção além de financiá-los. Eles preferiam que as relações entre os países se dessem não por meio de instituições, mas por relações multilaterais, com os EUA exercendo a liderança ${ }^{24}$ - Apesar dessas oposições, o congresso dos EUA aprovou a participação do país no FMI. Uma das explicações para isso é que havia um receio generalizado de uma nova depressão (tanto nos EUA como em outros países), de forma que os argumentos a favor de uma economia de livre mercado não tinham o espaço que tinham antes. Block (1977) destaca dois outros fatores. Primeiro, havia um amplo desejo pela estabilização da economia internacional e os EUA não poderiam deixar de fazer parte desse processo. Rejeitar tal papel, como havia ocorrido com a recusa de participar da Liga das Nações, afetaria a credibilidade internacional do país. Segundo, os EUA tinham poder de voto suficiente tanto para
22. The restoration of a multilateral financial system then depended in the view of almost every analyst on control of capital movements for an unlimited time.

23. Segundo Helleiner (1994), tendo emergido como os bancos líderes mundiais após a Guerra, os bancos de Nova York se beneficiariam de uma ordem financeira liberal.

24. Esse era um dos elementos do Plano da moeda chave (Key currency plan) de John H. Williams (então vice-presidente do Federal Reserve Bank of New York), uma proposta alternativa alinhada com os opositores dos Acordos de Bretton Woods. 
bloquear medidas que ele considerasse que pudessem ir contra seus interesses, como para mudar as regras do Fundo após sua aprovação. Ainda sim, é necessário ressalvar que com a morte de Roosevelt em 1945 e a chegada de Truman ao poder, o equilíbrio de poder para o gerenciamento das questões internacionais foi alterado a favor do Departamento de Estado em detrimento do Tesouro. No primeiro, prevaleciam visões contrárias aos Acordos de Bretton Woods, especialmente aos controles de capitais e a um papel mais ativo de instituições internacionais. Assim, por um breve período, entre 1945-1947, a estratégia dos EUA para o gerenciamento do SMI foi a de promover uma ordem financeira liberal (aos moldes do Plano da moeda chave), ignorando as regras acordadas em Bretton Woods (BLOCK, 1977). Segundo Helleiner (1994), nesse período a política externa econômica foi dominada pelos interesses da comunidade financeira de nova York, que pressionavam os países da europa ocidental a remover seus controles de capitais e o que se viu foi uma contínua fuga de capitais destes para os EUA. Em 1947, com a europa em crise econômica e com o início da Guerra Fria, os EUA se viram na necessidade de apoiar política intervencionistas que promovessem o crescimento em seus aliados da europa ocidental e no Japão, iniciando uma fase de "hegemonia benevolente". Só então tem início a promoção de uma ordem econômica internacional mais aos moldes do embedded liberalism e das diretrizes dos Acordos de Bretton Woods.

Considerações finais

Após a crise financeira de 2008, muito se falou sobre reformas profundas no SMI, mas elas se mostraram limitadas. Neste artigo buscou-se contribuir para a análise de mudanças no SMI de duas maneiras complementares. Primeiramente, buscando um arcabouço teórico que permitisse a integração entre economia e política, mostrando que as diferentes configurações do SMI têm implicações políticas e que é necessário um arcabouço que vá além da mera adição do balanço de poder entre os estados à análise econômica neoclássica. De acordo com a abordagem neogramsciana, mudanças no equilíbrio de poder não necessariamente implicariam mudanças nos regimes internacionais. Se, por um lado, deixa-se de lado a existência de um país dominante como condição necessária para a estabilidade do SMI, por outro coloca-se a hegemonia internacional como um fator essencial explicando a formação e o declínio dos diferentes sistemas.

Em segundo lugar, mostrando como o grande exemplo histórico de reforma institucional do SMI, os Acordos de Bretton Woods, foi fruto não apenas de um momento favorável a mudanças, mas também de um processo de adaptação de ideias e políticas às novas relações sociais vigentes nos países avançados e ao novo equilíbrio de poder entre os Estados. Ou seja, havia naquele momento uma nova hegemonia internacional, cuja construção se deu ao longo das décadas anteriores e teve de superar a oposição de setores poderosos.

No artigo, é defendido que um momento favorável pode ser condição necessária, mas não necessariamente suficiente para promover 
mudanças mais profundas. De nada adiantaria uma maior disposição política, ousadia e urgência em momentos de pânico se não houver ideias consolidadas a respeito do novo sistema que se deseja. Trazendo para a análise a questão dos países emergentes e da reforma do atual SMI, seria necessário que o maior peso econômico desses países viesse acompanhado do desejo por mudanças no SMI e que elas também fossem do interesse de outros países e de forças da sociedade civil que operam globalmente.

Em uma comparação do "momento Bretton Woods" com o atual, vale destacar que houve mudanças importantes no SMI após a crise, tanto por iniciativas individuais como multilaterais (). Em relação às individuais, muitos países buscaram se proteger da instabilidade dos fluxos de capitais pela acumulação de reservas internacionais e pelo uso de técnicas de gestão dos fluxos de capitais, que envolvem tanto controles de capitais como regulação financeira prudencial ${ }^{25}$. Já o FMI buscou melhorar as condicionalidades de suas linhas de auxílio, desenvolveu uma visão mais favorável ao uso de técnicas de gestão de fluxos ${ }^{26}$ e fez mudanças tanto no volume, como na distribuição de cotas (o que implica mudança no poder de voto entre os países) (SAMPAIO; WEISS, 2020). Quanto à sua "moeda", o direito especial de saque (DES), há propostas para o seu fortalecimento como ativo de reserva internacional ${ }^{27}$ e em 2009 houve uma grande emissão pelo FMI, mas a realidade é que seu papel no sistema continua marginal. Ainda nas mudanças cooperativas/multilaterais, a criação e o fortalecimento de arranjos financeiros regionais (AFRs) e de linhas de swap também ganharam grande impulso após a crise de 2008) (IMF, 2014) ${ }^{28}$. Os AFRs envolvem instrumentos como fundos conjuntos de reservas, acordos de swap e linhas de auxílio de curto prazo. Como exemplos de RFAs, temos a Iniciativa de Multilateralização de Chiang Mai (IMCM) da ASEAN $+3^{29}$, o Arranjo Contingente de Reservas, dos BRICS, o Arranjo de Swaps da Associação Sul-asiática para Cooperação Regional ${ }^{30}$ (SAARC), o Fundo de Estabilização e Desenvolvimento da Eurásia ${ }^{31}$ (EFSD) e o Mecanismo Europeu de Estabilidade Fiscal, que em 2012 se tornou o Mecanismo Europeu de Estabilidade. Finalmente, sobre as linhas de swap, segundo Denbee, Jung e Paternó (2016), em 2015 elas envolviam cerca de 42 países, em um total de 118 acordos. A China é o país com mais acordos, dispondo de linhas com 35 países, com valor estimado de US\$500 bilhões (MCDOWELL, 2019).

Embora se reconheça o potencial de tais mudanças para o SMI, é necessário também apontar suas limitações. A principal delas é que várias dessas medidas, especialmente a acumulação de reservas e as linhas de swap, reforçam o papel do dólar e, consequentemente, a assimetria de poder dos EUA no sistema. A segunda é que a mobilidade de capitais ainda é vista como algo a ser preservada no sistema, no máximo sendo mitigada pelo emprego de instrumentos de gestão de fluxos, cujo uso deveria ser que temporário e limitado. Em suma, é inegável que o momento após a crise de 2008 era propício a mudanças profundas, mas, mais de dez anos após seus momentos mais agudos, ainda estamos longe de uma transição hegemônica.
25. Conforme a definição de Epstein, Grabel e Jomo, 2004, p.3

26. Ver IMF (2016).

27. Ver Ocampo (2017).

28. 0 conjunto de instrumentos que envolvem reservas internacionais, instituições internacionais, AFRs e linhas de swap é chamado de rede global de proteção financeira.

29. Composta pelos países da ASEAN China, Coréia do Sul e Japão

30. Composta por Afeganistão, Bangladesh, Butão, Índia, Maldivas, Nepal, Paquistão e Sri Lanka.

31. Armênia, Belarus, Cazaquistão, Quirguistão, Rússia e Tajiquistão são os membros componentes. 
Referências

The Long twentieth century - Money, power and the origins of our times. London, New York: Verso, 1994

ARRIGHI, G. Adam Smith in Beijing. Lineages of the Twenty-First Century. London; New York: Verso, 2008.

BLOCK, F. The Origins of International Economic Disorder. Berkeley, Los Angeles, London: University of California Press, 1977.

COHEN, B. International Political Economy - An Intelectual History. Princeton and Oxford: Princeton University Press, 2008.

COX, R. W. Gramsci, Hegemony and International Relations: An essay in Method. Millennium: Journal of International Studies, v.12, n. 2, p. 162-175, 1981

COX, R. W. Social Forces, States and World Orders: Beyond International Relations Theory. Millennium: Journal of International Studies, v. 10, n. 2, p. 126-155, 1983

DENBEE, E.; JUNG, C.; PATERNÒ, F. Stitching together the global financial safety net. Financial Stability Paper. Bank Of England, n. 36, 2016.

EICHENGREEEN, B.. International Policy Coordination in Historical Perspective: A View From The Interwar Years. In: BUITER; W.; MARSTON, R. International Economic Policy Coordination. Cambridge: Cambridge University Press, 1985.

EICHENGREEN, B. Globalizing capital: a history of the international monetary system. 2. ed.. Princeton; Oxford: Princeton University Press, 2008.

EICHENGREEN, B.; FLANDREAU, M. The rise and fall of the dollar (or when did the dollar replace sterling as the leading reserve currency?). European Review of Economic History, p. 377-411, 2009.

EPSTEIN, G., GRABEL, I., JOMO, K. Capital management techniques in developing countries: an assessment of experiences from the 1990s and lessons for the future. G-24 Discussion Paper, n. 27, 2004.

FEDERAL RESERVE BOARD. Federal Reserve Bulletin, jun. 1922. Disponível em: http:// fraser.stlouisfed.org/docs/publications/FRB/1920s/frb_061922.pdf. Acesso em: 29 nov. 2019.

FINK, C. The Genoa Conference. Chapel Hill; London: University of North Carolina Press, 1984.

FIORI, J. Formação, Expansão e Limites do Poder Global. In: FIORI,J.L. O Poder Americano. 2. ed.. Petrópolis: Vozes, 2005.

GILL, S. American Hegemony and the trilateral commission. Cambridge: Cambridge University Press, 1990.

GILPIN, R. The Politics of Transnational Economic Relations. International Organization, v. 25, n. 3, p. 398-419, 1971.

GILPIN, R. Global Political Economy. Understanding the international economic order. Princeton e Oxford: Princeton University Press, 2001.

HELLEINER, E. States and the reemergence of global finance from Bretton Woods to the 1990's. Ithaca and London: Cornell University Press, 1994.

HELLEINER, E. A Bretton Woods moment? The 2007-2008 crisis and the future of global finance. International Affairs, v. 86, n. 3, p. 619-636, 2010.

HOBSBAWM, E. Age o Extremes. The Short Twentieth Century 1914-1991. London: Abacus, 1995.

IMF. Capital flows: review of experience with the institutional view. IMF Policy Paper. Press Release n. 16/573, 2016.

JAMES, H. International Monetary Cooperation Since Bretton Woods. Washington, D.C.; Oxford: Oxford University Press, 1996.

KEOHANE, R. O. After hegemony: Cooperation and discord in the world political economy. Princeton and New Jersey: Princeton Univ. Press, 1984.

KEOHANE, R.; NYE, J. S. Power and Interdependence. London: Harper Colins, 1989

KEYNES, J. A União Internacional de Compensações. In: SZMRECSÁNYI, T. KEYNES. São Paulo: Ática, 1984. 
KINDLEBERGER, C. World in Depression 1929-1939. Middlesex: Penguin, 1987.

KRASNER, S. State Power and the Structure of International Trade. World Politics, v. 28, n. 3, p. 317-347, 1976.

KRASNER, S. Structural causes and regime consequences: regimes as intervening variables. International Organization, v. 3, n. 2, p. 185-205, 1982

McDOWELL, D. The (Ineffective) Financial Statecraft of China's Bilateral Swap Agreements. Development and Change, v. 50, n. 1, p. 122-143, 2019.

OCAMPO, J. Reseting the international Monetary (non) System.Oxford: Oxford University Press, 2017.

POLANYI, K. The Great transformation:The Political and Economic Origins of Our Time. Boston: Beacon University Press, 2001.

RUGGIE, J. International regimes, transactions and change: embedded liberalism in the postwar economic order. International Organization, v. 36, n. 2, p. 379-405,1982.

RUGGIE, J. What Makes the World Hang Together? Neo-Utilitarianism and the Social Constructivist Challenge. International Organization, v. 52, n. 4, p. 855-885, 1998.

RUPERT, M. Marxism and critical theory. In: DUNNE, T.; KURKI, M.; SMITH, S. International Relations Theory: Discipline and diversity. 2. ed. New York: Oxford University Press, 2010.

SAMPAIO, A.V.; WEISS, M.A.. A instabilidade do sistema monetário internacional e estratégias recentes dos países emergentes. Revista da Sociedade Brasileira de Economia Política, v. 57, p. 11-44, 2020.

SCANDIUCCI FILHO, J. G. Hegemonia, Estados e Mercado nos arranjos de Bretton Woods. Tese (Doutorado em Economia), Instituto de Economia, Universidade Estadual de Campinas, Campinas, 2000.

STRANGE, S. International Monetary Relations. In: SHONFIELD, A. International Economic Relations of the Western World 1959-1971. The Royal Institute of International Affairs.. London; New York; Toronto: Oxford University Press, 1976.

STRANGE, S. The retreat of the state. The diffusion of power in the world economy. Cambridge: Cambridge University Press, 1996.

WALLERSTEIN, I. World-Systems Analysis: an Introduction. Durham; London: Duke University Press, 2004.

WALTZ, K. N. Theory of International Politics. Reading: Addison-Wesley, 1979.

WARNAAR, M. Gramsci’s Bridges: A Dialectical Approach to International Studies. International Studies Review, v. 14, n. 4, p. 666-686, 2012. 